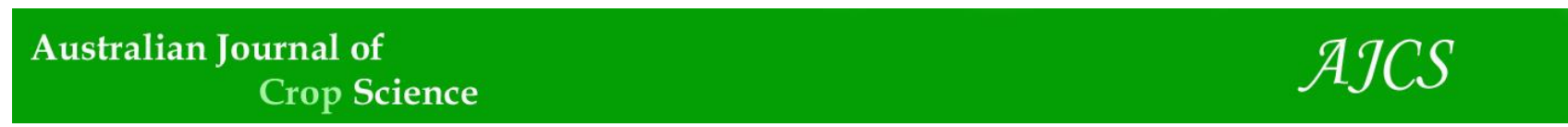

AJCS 12(05):704-710 (2018)

ISSN:1835-2707

doi: 10.21475/ajcs.18.12.05.PNE754

\title{
Cerium (Ce) and Lanthanum (La) promoted plant growth and mycorrhizal colonization of maize in tropical soil
}

\author{
Laíze Aparecida Ferreira Vilela', Sílvio Junio Ramos², Marco Aurélio Carbone Carneiro ${ }^{3}$ Valdemar Faquin ${ }^{3}$, \\ Luiz Roberto Guimarães Guilherme ${ }^{3}$, José Oswaldo Siqueira ${ }^{2,3^{*}}$
}

'Centro de Ciência Natural, Universidade Federal de São Carlos, Rodovia Lauri Simões de Barros, km 12 SP-189, Bairro Aracaçu, Buri, São Paulo, 18290-000, Brazil

${ }^{2}$ Instituto Tecnológico Vale, Rua Boaventura da Silva, 955, Belém, Pará, 66055-090, Brazil

${ }^{3}$ Departamento de Ciência do Solo, Universidade Federal de Lavras, Lavras, Minas Gerais, 37200-000, Brazil

*Corresponding Author: jose.oswaldo.siqueira@itv.org

Abstract

Rare earth elements, such as lanthanum (La) and cerium (Ce), have been employed as agricultural inputs in some countries to enhance yield and crop quality. Benefits of arbuscular mycorrhizal fungi (AMF) inoculation for maize are also well established, but effects of inoculation in coapplication with La and Ce are largely unknown. In the current study, the effects of La and Ce application were evaluated in two separate experiments, in soil and seed treatments. Both studies were performed using a completely randomized design in a $6 \times 2$ factorial scheme, with four replicates. Plants were exposed to the following concentrations (mg $\mathrm{dm}^{-3}$ as soil application): $\mathrm{La}-0,20,40,60,80$, and 100; and Ce - 0, 25, 50, 75, 100, and 125; and (mg L ${ }^{-1}$ as seed application) 0, 6, 12, 18, 24, and 30 for both elements, in presence and absence of AMF inoculations. Both elements enhanced maize growth, mainly at 60 and $40 \mathrm{mg} \mathrm{dm}^{-3}$ doses for soil application, and 15 and $10 \mathrm{mg} \mathrm{L}^{-1}$ doses for seed treatment, for La and Ce respectively. Moreover, at lower doses, both elements stimulated AMF colonization. A synergistic relationship was also observed between AMF, Ce and La on growth of maize. Results provided relevant information on Ce and La effects on maize growth in tropical environments, suggesting that application of these rare earth elements in soils containing AMF propagules is promising to improve crop production in tropical soils.

Keywords: rare earth elements; REE; arbuscular mycorrhizal fungi; plant growth

Abbreviations: Ce_Cerium, La_Lanthanum, AMF_Arbuscular mycorrhizal, REE_Rare earth elements.

Introduction

Rare earth elements (REE) are defined as a homogenous group of 17 chemical elements belonging to group $3 \mathrm{~A}$ of the periodic table, with similar physical and chemical properties, including 15 elements with atomic numbers from 57 to 71 , i.e., from lanthanum (La) to lutetium (Lu) (called lanthanides), plus scandium and yttrium. Cerium (Ce) La are the most abundant REE in soils (Kabata-Pendias and Mukherjee, 2007). These elements can be found in several minerals, including apatite, which is a key raw material for production of phosphate fertilizers. REE content in apatitic materials (phosphate rocks and phosphate concentrates) and in products derived from them may vary in terms of mineralogy and origin (Ramos et al., 2016a). REE have been applied to Chinese soils on purpose, through enrichment of fertilizers with these elements (Liu et al., 2006; Ren et al., 2016). Phosphate fertilizers may significantly vary in REE concentration, and their presence may affect crop yield and deposition in agricultural soils (Ramos et al. 2016b). This aspect is particularly relevant in tropical soils, which generally require large amounts of phosphate fertilizers for adequate crop yields (Lopes and Guilherme, 2016). Therefore, it is of great interest to know the effects of these elements on crops and processes related to their role on plant growth.
Previous studies have determined that REE stimulate plant growth and yield, as well as enhance product quality of several crops. Such effects have been mainly due to the increase in the photosynthetic activity (Oliveira et al., 2015; Ramos et al., 2016b; Shyam and Aery, 2012). On the other hand, these elements may exhibit phytotoxicity under high REE concentrations, reducing root elongation and causing nutrient imbalances (Chen and Zhao, 2007). Information concerning beneficial or deleterious effects is not available for soil in tropical agroecosystems. Therefore, given the major Brazilian role as a leading crop producer and exporter, as well as the need of heavy fertilizer applications in soils to sustain yields, it is important to better understand the REE effects on soil quality and crop growth.

It was suggested that REE accumulation in soil might impair plant growth through interference with microbial processes and function of microorganisms (Fitriyanto et al., 2011). This includes plant-microorganism relations, such as the root-fungus symbiosis called mycorrhiza, known to play an important role in agriculture. Arbuscular mycorrhizal are widespread in tropical soils and crops, and known to improve mineral nutrition as well as increase plant tolerance to biotic and abiotic stresses (Siqueira et al., 2007). This symbiosis significantly influences absorption of many trace 
elements by plants, and may affect the role of REE on plant growth. It is also possible that these elements affect mycorrhizal colonization and thus the benefits of such symbiosis to crops.

The current study evaluated the growth of maize plants in response to inoculation with mycorrhizal fungi, application of La and Ce in soil, as well as seed treatments. With that, the role of these REE in plant growth can be unveiled. This aspect is quite relevant since these elements have been applied inadvertently already via phosphate fertilizers, especially for crop production systems in oxidic soils.

\section{Results}

\section{Plant responses to Ce and La application}

Lanthanum and $\mathrm{Ce}$ in soil and seed application influenced maize growth and mycorrhizal colonization in different ways. These effects varied according to element, concentration and AMF inoculation (Fig. 1 and 2). Ce soil application equivalent to $57.39 \mathrm{mg} \mathrm{dm}^{-3}$ in plants inoculated with AMF increased shoot dry matter by $38 \%$ in relation to the control (Fig. 1a). A similar response was observed for non-AMF plants. Inoculation with AMF enhanced plant growth for all Ce doses, either in soil or in seed application (Fig. 1a, d). Cerium in seed application was negligible on shoots dry weight of inoculated plants, even at high doses, whereas non-AMF plants showed a reduction of shoot dry matter at high Ce doses (Fig. 1d). Root dry weight response to Ce was not affected by AMF and reached its maximum with 65.17 $\mathrm{mg} \mathrm{dm} \mathrm{m}^{-3}$ of Ce (Fig. 1b), while root growth in AMF-inoculated plants increased by $12 \%$ in relation to non-inoculated plants (Table 1). Cerium showed positive response on root growth in seed application, with such effect being more pronounced in non-AMF plants. It is worth mentioning that plants inoculated with AMF in all Ce doses applied via seeds presented high root development, except for the highest dose of Ce (Fig. 1e). In addition, the chlorophyll index was affected by treatments. Soil application of $61.55 \mathrm{mg} \mathrm{dm}^{-3}$ of Ce promoted a maximum level of chlorophyll index (Fig. 1c). AMF inoculation also increased this variable (Table 1), but no interaction between concentration and AMF was found. AMF plants also showed greater chlorophyll index in seed application than non-AMF plants, especially at higher $\mathrm{Ce}$ doses.

Effects of La in soil and seed application are presented on Fig. 2 and Table 1. It was observed that La applied in soil or in seed promoted significant effects and responses in relation to effects observed for Ce. Lanthanum effects on plant growth and chlorophyll index were quite evident, reaching up to $40 \%$ in shoot dry weight (Table 1). No effect was found for La on root dry matter. AMF inoculation promoted better root development (Fig. 2d) with an increase of $23 \%$ as compared to non-AMF plants (Table 1 ). Increasing La application via seed treatment had negligible effect on root growth in AMF plants, but exhibited negative effect in non-AMF plants (Fig. 2e). Chlorophyll index increased in the presence of La, but such effect was quite low. When Ce and La were applied at high doses, there was a decrease of shoot and root biomass. These results were associated with roots thickening and reduction of the amount of root trichrome, which an excess of these elements possibly affecting nutrient absorption and mycorrhizal colonization of maize plants.

\section{Effects of Ce and La on mycorrhizal colonization}

Fig. 3 summarizes effects of Ce and La doses applied in soil and seed on maize plants mycorrhizal colonization. The colonization degree was high for experimental conditions and showed a quadratic response to both elements. Cerium was more active in stimulating AMF colonization in maize plants than La. Maximum colonization was achieved for the same concentration range observed for maximum effects on plant growth. The effect of La on colonization was quite low when this element was applied via seed. Although the mechanisms involved in these effects cannot be addressed, results reported in this study were quite relevant and thus deserve further specific investigation.

\section{Effects of Ce and La doses on their concentrations in maize plants}

Levels of $\mathrm{Ce}$ and $\mathrm{La}$ in roots and shoots of maize are presented on Fig. 4 and 5 . Contents of $\mathrm{Ce}$ and La in the certificate standard BCR ${ }^{\circledR}$ 670-Aquatic Plant (IRMM, Geel, Belgium) presented a mean recovery of $94 \%$ for $\mathrm{Ce}$ and $95 \%$ for La, demonstrating accuracy and quality of the data obtained. Application of $\mathrm{Ce}$ and $\mathrm{La}$ in different doses markedly increased their concentration in maize. Such effects were linear or quasi-linear as a function of concentration applied to the soil, whereas the responses were different when these elements were applied as seed treatment. AMF effects were found only at the two highest Ce doses applied to soil. Cerium concentration in maize was significantly affected by AMF inoculation (Table 1). Similar to $\mathrm{Ce}$, La application at increasing doses also increased its concentration in maize roots and shoots. However, such response exhibited different shapes and AMF effects for both elements. In general, Ce and La plant concentration were higher by a 100 -fold when they were supplied in soil versus seeds. At the highest doses of $\mathrm{Ce}$ and La applied in soil, an average of 1.2 and $1.8 \mathrm{mg} \mathrm{kg}^{-1}$ in shoots, and 70 and $40 \mathrm{mg} \mathrm{kg}^{-1}$ in roots, were observed for Ce and La, respectively. Total levels of $\mathrm{Ce}$ and $\mathrm{La}$ in shoots and roots showed over 10- and 15-fold increase for shoot and root, respectively. Concentrations of these elements in roots were much higher than shoots, indicating poor $\mathrm{Ce}$ and La translocation in maize plants.

\section{Discussion}

Rare earth elements (REE) have been especially used in Chinese agriculture since the 1980's to improve crop yields (Liu et al., 2006). Mechanisms by which REE stimulates plant growth have yet not been clarified. AMF symbioses is well known to affect trace element uptake by plants, but their effects on REE uptake have not been investigated in tropical soils. This study reports positive effects of $\mathrm{La}$ and $\mathrm{Ce}$ application on growth of maize in the presence and absence of AMF in soil. Cerium and La are commonly present in phosphate fertilizers and phosphogypsum, and thus these soil amendments have been identified as potential REE nonpoint sources to Brazilian soils (Ramos et al., 2016a). Different application forms of Ce and La and the presence or 
Table 1. Shoot dry weight, root dry weight, chlorophyll index, and Ce and La concentration in maize affected by Ce and La in soil and seed application, with mycorrhizal inoculation.

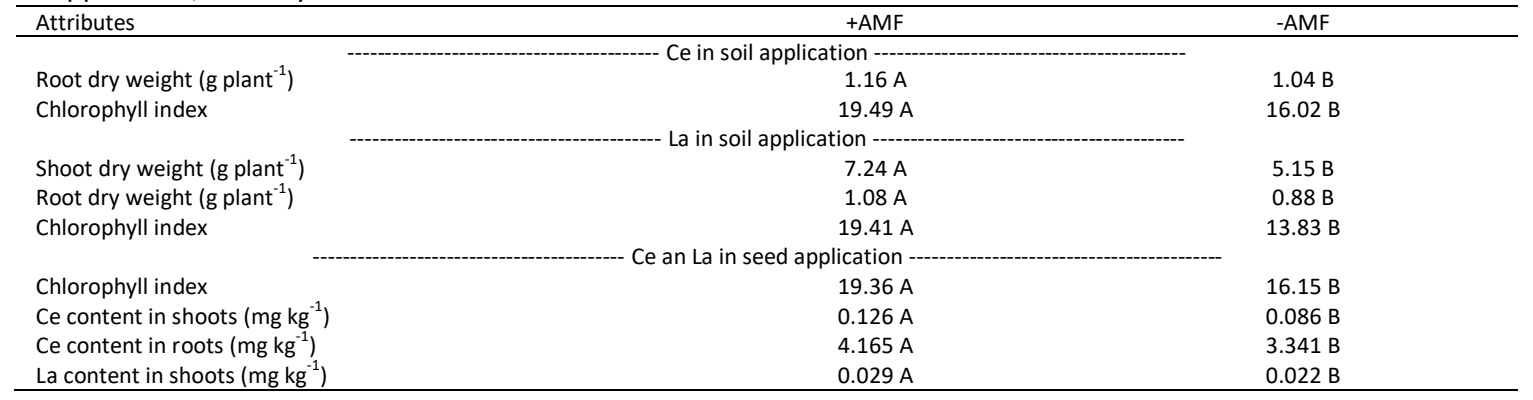

+AMF: with AMF inoculation; -AMF: without AMF inoculation. Different letters in the row indicate differences between inoculated (+AMF) and non-inoculated (-AMF) treatment means, according to the Tukey test $(p \leq 0.05)$.

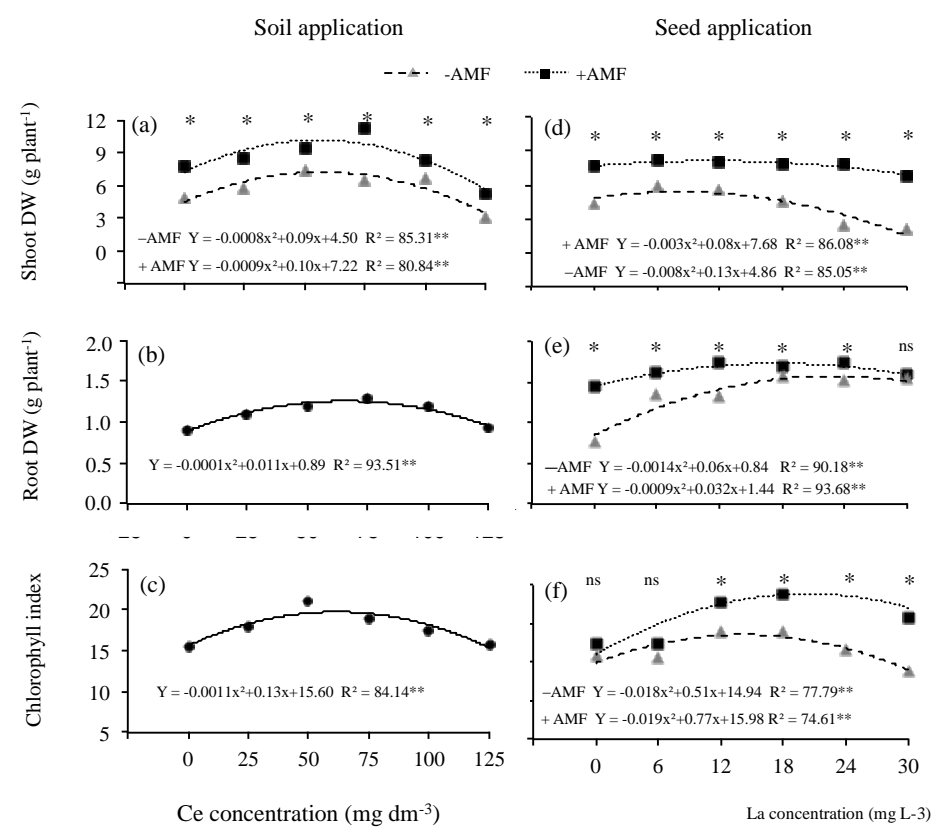

Fig 1. Shoot dry weight, root dry weight, and chlorophyll index in maize affected by Ce in soil $(a, b, c)$ and seed (d, e, f) application

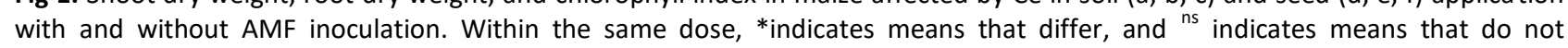
significantly differ between treatments with and without AMF, by the Tukey test at $5 \%$ probability.

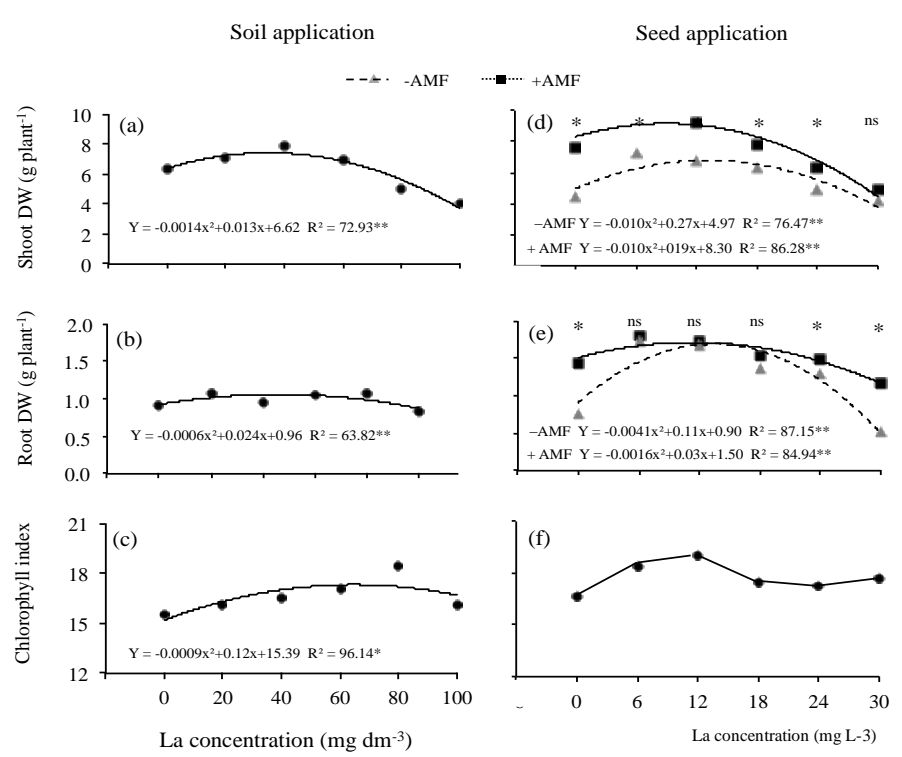

Fig 2. Shoot dry weight, root dry weight, and chlorophyll index in maize affected by La soil (a, b, c) and seed (d, e, f) application with and without AMF inoculation. Within the same dose, ${ }^{*}$ indicates means that differ, and ${ }^{\text {ns }}$ indicates means that do not significantly differ between treatments with and without AMF, by the Tukey test at $5 \%$ probability. 

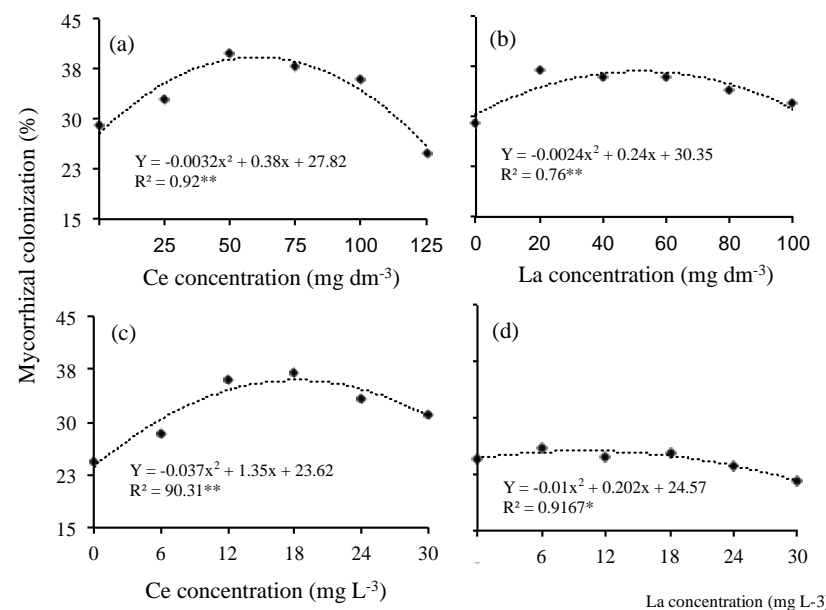

Fig 3. Mycorrhizal colonization of maize plants to increasing doses of $\mathrm{Ce}$ and La in soil (a, b) and in seed (c, d) with mycorrhizal inoculation. *Significant at $5 \%$; ** Significant at $1 \%$.

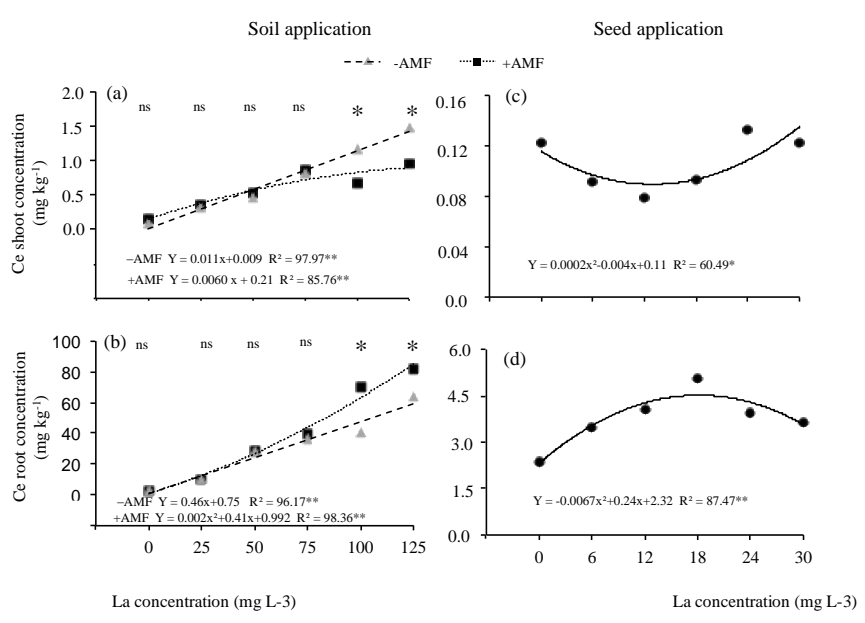

Fig 4. Levels of $\mathrm{Ce}$ in response to soil application $(a, b)$ and seed application (c, d) of maize plants. Within the same dose, *indicates means that differ, and ${ }^{\text {ns }}$ indicates means that do not significantly differ between treatments with (+ Mic) and without (-Mic) AMF, by the Tukey test at $5 \%$ probability.

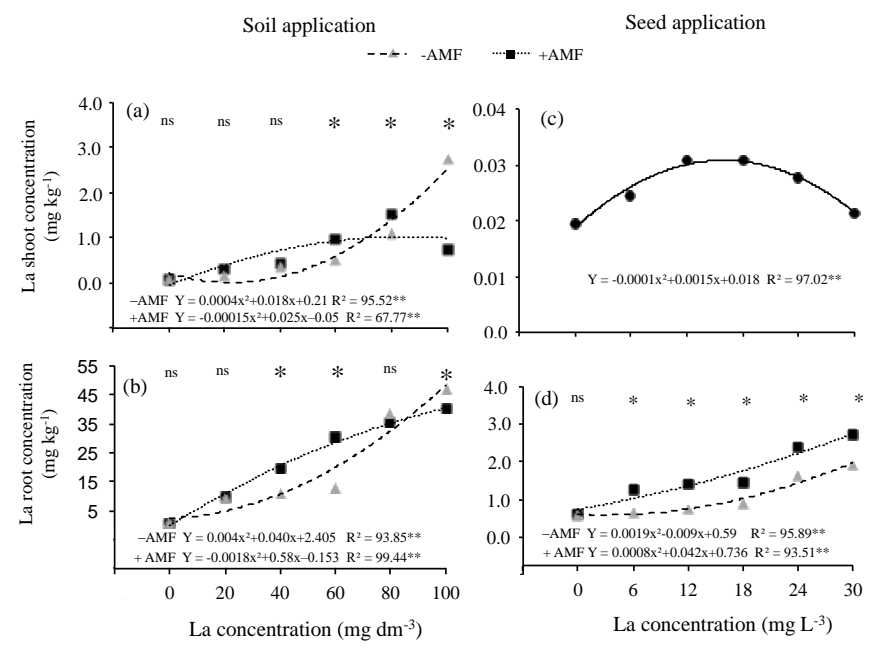

Fig 5. Levels of La in response to soil application $(a, b)$ and seed application (c, d) of maize plants. Within the same dose, *indicates means that differ, and ${ }^{\text {ns }}$ indicates means that do not significantly differ between treatments with (+ Mic) and without (-Mic) AMF, by the Tukey test at $5 \%$ probability. 
absence of AMF resulted in differentiated effects on maize growth, especially when La and Ce were applied via soil at intermediate doses.

Although $\mathrm{Ce}$ and La are not considered as essential or beneficial elements for plant growth, results show that the use of intermediate doses of Ce and La, at 57 and $34 \mathrm{mg} \mathrm{dm}^{-}$ ${ }^{3}$, respectively as soil application, or $11 \mathrm{mg} \mathrm{dm}^{-3}$ of Ce and 9 $\mathrm{mg} \mathrm{dm^{-3 }}$ of La as seed application, promoted maize growth, mainly in AMF presence. These results are in agreement with other studies carried out with different crops and soils (Emmanuel et al., 2010a; Shyam and Aery, 2012; Zhou et al., 2011). Due to their physical and chemical similarities, La and Ce appear to act similarly in plants, leading to competition or substitution of $\mathrm{Ca}$ in plant functions as suggested by Hu et al. (2004), Xie et al. (2002), and Liu et al. (2013), whom considered that this substitution may promote plant structural changes and therefore interfere on plant growth. This was actually observed when maize was allowed to grow in high doses of La and Ce.

Ce and La soil application resulted in higher levels of these elements in maize plants than seed application. This is due to the fact that the amounts applied in the soil were much higher than those via seeds. In both forms of application, concentrations of $\mathrm{Ce}$ and La were significantly higher in roots than shoots. These results are consistent with others observed in prior studies, which reported that REEs tend to remain in the roots, and less than $5 \%$ are translocated into the shoots (Hu et al., 2002; Emmanuel et al., 2010b; Oliveira et al., 2015; Wang et al., 2001). Plants have several different strategies to control redistribution of nutrient or other elements, especially those related to the presence of apoplastic barriers in the roots. Initially, at high availability, these barriers are the first obstacles hindering these elements to reach the xylem, thus hampering their translocation to other plant organs. It is interesting to note that under higher doses of $\mathrm{Ce}$ and La in the soil, AMF inoculation decreased the levels of these elements in the shoot, but caused an increase in roots. Such behavior highlights the protective effect of AMF on plants exposed to high levels of $\mathrm{Ce}$ and La in the soil. These results indicate the probable temporary immobilization of $\mathrm{Ce}$ and $\mathrm{La}$ in the mycelium, which consequently reduces the translocation of these elements to the shoot. Furthermore, Ce and La may have been immobilized through chelate formation in the rhizosphere with compounds such as histidine, organic acids, and glomalin, and/or were also retained in fungal structures, such as cell wall, hyphae vacuoles, and spores (Cabral et al., 2015). Plants inoculated with AMF and exposed to La in soil showed higher concentrations of La in shoots at intermediate doses than non-inoculated plants. On the other hand, at the highest La dose, AMF inoculation reduced La levels. A similar response was observed for roots. In both cases, effects of AMF seem to be related to mechanisms that promote the exclusion of this element, such as the release of substances that alter the soil-rhizosphere environment and promote their precipitation, chelation, and/or soil adsorption (Rashid et al., 2009).

Application of Ce and La at intermediate doses stimulated mycorrhizal colonization of maize in both forms of application. Results obtained by Chen and Zhao (2007) were different from this study. These authors found that the application of $20 \mathrm{mg} \mathrm{dm}^{-3} \mathrm{La}$ in the soil reduced the colonization from $80 \%$ to $32 \%$ to, depending on the AMF species. On the other hand, Guo et al. (2013) found no alteration in colonization rate in the presence of REE in mine tailings. At $\mathrm{Ce}$ and La high doses, there was a reduction in mycorrhizal colonization. These findings are in agreement with other studies that reported reduction of mycorrhizal colonization on high concentrations of trace elements (Chen and Zhao, 2007).

Positive effects of $\mathrm{Ce}$ and La on maize AMF colonization increase were high and consistent. This may represent a mechanism by which these elements enhance plant growth. Studies dealing with such REE in crop plants, and particularly those focusing on their interaction with AMF have a great interest considering the fact that the biological role of REE is still a matter of discussion (Skovran and Martinez-Gomez, 2015). These aspects need to be investigated further.

\section{Materials and methods}

\section{Experimental design and plant cultivation}

This study consisted of two separate experiments, one with La and $\mathrm{Ce}$ in soil application, and the other as seed application. Both studies were performed in a completely randomized design in a $6 \times 2$ factorial scheme, with four replicates, using six different doses of La and $\mathrm{Ce}$, with and without arbuscular mycorrhizal fungi inoculation, with propagules applied in the soil.

Cerium and La were applied in a soluble form as nitrate hexahydrate $\left[\mathrm{La}\left(\mathrm{NO}_{3}\right)_{3} \cdot 6 \mathrm{H}_{2} \mathrm{O}\right.$ and $\mathrm{Ce}\left(\mathrm{NO}_{3}\right)_{3} \cdot 6 \mathrm{H}_{2} \mathrm{O}$ ], using $99 \%$ purity Sigma Aldrich salts. Due to the presence of $\mathrm{N}$ in the La and $\mathrm{Ce}$ sources, $\mathrm{N}$ doses were balanced by means of a nutrient solution containing $\mathrm{NH}_{4} \mathrm{NO}_{3}$. Thus, the amount of $\mathrm{N}$ applied in all treatments was the same. Plants were exposed to the following concentrations ( $\mathrm{mg} \mathrm{dm}^{-3}$ as soil application): La - 0, 20, 40, 60, 80, and 100; and Ce - 0, 25, 50, 75, 100, and 125; and ( $\mathrm{m} \mathrm{L}^{-1}$ as seed application) $0,6,12,18,24$, and 30 for both elements. These doses were established through pre-trials in a greenhouse, which allowed the selection of the most appropriate doses to evaluate the effects of these elements on plant growth, on colonization, and on mycorrhizae benefits. For seed application, doses of each REE were based on the study of Espindola et al. (2013), i.e., $0,6,12,18,24$, and $30 \mathrm{mg} \mathrm{L}^{-1}$ for each REE. In this experiment, seeds were soaked in a solution with each REE with their respective concentration, in a volume equivalent to 1.5 times the weight of the seeds, for one hour, and then dried with a paper towel.

A Dystrophic Red Latosol (Oxisol) was the soil used for testing REE application, which was collected in a layer below $60 \mathrm{~cm}$, in order to ensure the absence of REE, that could have been added by phosphorus fertilization. The soil had the following characteristics: $\mathrm{pH}$ (water) $=5.8 ; \mathrm{H}^{+}+\mathrm{Al}^{3+}=1.49$ $\mathrm{cmol}_{\mathrm{c}} \mathrm{dm}^{-3} ; \mathrm{Ca}^{2+}=0.10 \mathrm{cmol}_{\mathrm{c}} \mathrm{dm}^{-3} ; \mathrm{Mg}^{2+}=0.10 \mathrm{cmol}_{\mathrm{c}} \mathrm{dm}^{-3} ; \mathrm{K}$ $=16.00 \mathrm{mg} \mathrm{dm}^{-3} ; \mathrm{P}=0.28 \mathrm{mg} \mathrm{dm}^{-3} ; \mathrm{MO}=6.5 \mathrm{~g} \mathrm{~kg}^{-1} ;$ sand $=$ $180 \mathrm{~g} \mathrm{~kg}^{-1}$; silt $=140 \mathrm{~g} \mathrm{~kg}^{-1}$; clay $=680 \mathrm{~g} \mathrm{~kg}^{-1}$. Prior to AMF inoculation and cultivation, the soil was autoclaved at 120 degrees for 1 hour, during two consecutive days. Subsequently, soil acidity correction was performed with addition of $\mathrm{CaCO}_{3}$ and $\mathrm{MgCO}_{3}$ (3:1), in order to increase base saturation to $50 \%$ (Ribeiro et al., 1999). Then the soil was placed in $1 \mathrm{~kg}$ pots and allowed to rest for 30 days.

AMF inoculation was performed with a soil-inoculum composed of Gigaspora gigantea, Scutellospora 
heterogama, and Acaulospora scrobiculata species, in equal proportion, deposited below maize seeds, providing 150 spores pot ${ }^{-1}$, besides hyphae and colonized roots. Soilinoculum was obtained from pots cultivated with Brachiaria brizantha of the Arbuscular Mycorrhizal Collection from the Universidade Federal de Lavras, Brazil. Non-inoculated treatments (AMF) received $5 \mathrm{~mL}$ of the filtered suspension of the soil-inoculum to provide the same microbial population, but without AMFs.

Soil fertilization was done as recommended for maize and pot fertilization (Ribeiro et al., 1999), by adding $300 \mathrm{dm}^{-3} \mathrm{~N}$, $250 \mathrm{mg} \mathrm{dm}^{-3} \mathrm{P}, 300 \mathrm{mg} \mathrm{dm}^{-3} \mathrm{~K}, 50 \mathrm{mg} \mathrm{dm}^{-3} \mathrm{~S}$, and $7.5 \mathrm{mg} \mathrm{dm}^{-}$ ${ }^{3} \mathrm{Zn}$. All pots received solutions containing doses of each REE studied, which were homogenized. Subsequently, the soil was inoculated with AMFs, and maize seeds were sown (hybrid Dow AgroSciences 2B810), allowing the growth of only 1 plant pot ${ }^{-1}$. Irrigation was done daily, with humidity kept at $60 \%$ field capacity.

\section{Analytical procedures}

Maize shoots and roots from both experiments were harvested separately after 60 days of cultivation, washed thoroughly with distilled water and then oven-dried at $70^{\circ} \mathrm{C}$ until they reached a constant mass. Mean weight and standard errors were calculated to infer significant differences among treatments. During harvesting, chlorophyll index was evaluated in the last two fully expanded leaves of maize plants, using a SPAD Minolta device (Markwell et al., 1995). One gram of fine roots was collected, washed, clarified with $10 \% \mathrm{KOH}$, and stained with Trypan Blue (Koske and Gemma, 1989) for evaluation of mycorrhizal colonization, according to the method by Giovannetti and Mosse (1980).

In order to determine La and Ce concentrations, roots and shoots were initially ground and digested according to the 3051A method (USEPA, 2007). A certified reference material identified as $B{ }^{\circledR}$ 670-Aquatic Plant was employed (Institute for Reference Materials and Measurements IRMM, Geel, Belgium). Blank samples were included in the analysis for quality control. Ce and La concentrations were determined through an Inductively Coupled Plasma Mass Spectrometer (ICP-MS).

\section{Statistical analysis}

Data were subjected to a variance analysis (ANOVA), linear regression (5\%), and Pearson correlation. All statistical analyses were performed on $\mathrm{R}$ environment ( $\mathrm{R}$ Core Team, 2016).

\section{Conclusion}

Cerium and La, regardless of the application method significantly enhanced maize growth, mainly at Ce doses of 60 and $15 \mathrm{mg} \mathrm{dm}^{-3}$, and 40 and $10 \mathrm{mg} \mathrm{kg}^{-3}$ of La, for soil and seed application, respectively. In addition, a synergistic relationship between $\mathrm{AMF}$, and $\mathrm{Ce}$ and La on growth of maize was observed. Results provided relevant information on effects of Ce and La on maize growth in tropical environments, suggesting that application of these rare earth elements in soils containing AMF propagules is promising to improve crop production in tropical soils.

\section{Acknowledgments}

This study was financially supported by Instituto Tecnológico Vale, in cooperation with the Universidade Federal de Lavras (Grant No. 020/2012), as well as CNPq (Grant No. 406806/2013-6; 308105/2014-1), and FAPEMIG (Grant No. RDP-00033-10).

\section{References}

Cabral C, Soares CRFS, Giachini AJ, Siqueira JO (2015) Arbuscular mycorrhizal fungi in phytoremediation of contaminated areas by trace elements: mechanisms and major benefits of their applications. World J Microbiol Biotechnol. 31(11): 1655-1664.

Chen XH, Zhao B (2007) Arbuscular mycorrhizal fungi mediated uptake of lanthanum in Chinese milk vetch (Astragalus sinicus L.). Chemosphere. 68(8): 1548-1555.

Emmanuel ESC, Anandkumar B, Natesan M, Maruthamuthu $S$ (2010a) Efficacy of rare earth elements on the physiological and biochemical characteristics of Zea mays L. Aust J Crop Sci. 4(4): 289-294.

Emmanuel ESC, Ramachandran A, Ravindran AD, Natesan M, Maruthamuthu S (2010b) Effect of some rare earth elements on dry matter partitioning, nodule formation and chlorophyll content in Arachis hypogaea L. plants. Aust J Crop Sci. 4(9): 670-675.

Espindola MCG, de Menezes NL, Barbieri APP (2013) Efeito do cério na qualidade fisiológica de sementes de milho e no desempenho agronômico das plantas. Bioscience J. 29(5): 1501-1507.

Fitriyanto NA, Nakamura M, Muto S, Kato K, Yabe T, Iwama T, Kawai K, Pertiwiningrum A (2011) $\mathrm{Ce}^{3+}$-induced exopolysaccharide production by Bradyrhizobium sp MAFF211645. J Biosci Bioeng. 111(2): 146-152.

Giovannetti M, Mosse B (1980) An evaluation of techniques for measuring vesicular arbuscular mycorrhizal infection in roots. New Phytol. 84(3): 489-500.

Guo W, Zhao R, Zhao W, Fu R, Guo J, Bi N, Zhang J (2013) Effects of arbuscular mycorrhizal fungi on maize (Zea mays L.) and sorghum (Sorghum bicolor L. Moench) grown in rare earth elements of mine tailings. Appl Soil Ecol. 72: 8592.

Hu Z, Richter H, Sparovek G, Schnug E (2004) Physiological and biochemical effects of rare earth elements on plants and their agricultural significance: a review. J Plant Nutr. 27(1): 183-220.

Kabata-Pendias A, Mukherjee AB (2007) Trace elements from soil to human. Springer Berlin Heidelberg, New York.

Koske R, Gemma J (1989) A modified procedure for staining roots to detect VA mycorrhizas. Mycol Res. 92(4): 86-488.

Liu XS, Wang JC, Yang J, Fan YB, Wu YP, Zhang H (2006) Application of rare earth phosphate fertilizer in Western area of China. J Rare Earths. 24(1): 423-426.

Liu D, Wang X, Zhang X, Gao Z (2013) Effects of lanthanum on growth and accumulation in roots of rice seedlings. Plant Soil Environ. 59(5): 196-200.

Lopes AS, Guilherme LRG (2016) A Career Perspective on Soil Management in the Cerrado Region of Brazil. In: Donald LS (ed) Adv Agron. 137: 1-72.

Markwell J, Osterman JC, Mitchell JL (1995) Calibration of the Minolta SPAD-502 leaf chlorophyll meter. Photosynth Res. 46(3): 467-472. 
Oliveira C, Ramos SJ, Siqueira JO, Faquin V, Castro EM, Amaral DC, Techio VH, Coelho LC, Silva PHP, Schnug E, Guilherme LRG (2015) Bioaccumulation and effects of lanthanum on growth and mitotic index in soybean plants. Ecotoxicol Environ Saf. 122: 136-144.

Ramos SJ, Dinali GS, de Carvalho TS, Chaves LC, Siqueira JO, Guilherme LR (2016a) Rare earth elements in raw materials and products of the phosphate fertilizer industry in South America: Content, signature, and crystalline phases. J Geochem Explor. 168: 177-186.

Ramos SJ, Dinali GS, Oliveira C, Martins GC, Moreira CG, Siqueira JO, Guilherme LR (2016b) Rare earth elements in the soil environment. Curr Pollut Rep. 2(1): 28-50.

Rashid A, Ayub N, Ahmad T, Gul J, Khan AG (2009) Phytoaccumulation prospects of cadmium and zinc by mycorrhizal plant species growing in industrially polluted soils. Environ Geochem Health. 31(1): 91-98.

Ren Y, Ren X, Ma J, Yan L (2016) Effects of mixed rare earth fertilizer on yield and nutrient quality of leafy vegetables during different seasons. J Rare Earth. 34(6): 638-643.

Ribeiro AC, Guimarães PTG, Alvarez V. VH (1999) Recomendações para o uso de corretivos e fertilizantes em Minas Gerais. 5th ed. Comissão de fertilidade do solo do estado de Minas Gerais, Viçosa.
Shyam R, Aery N (2012) Effect of cerium on growth, dry matter production, biochemical constituents and enzymatic activities of cowpea plants [Vigna unguiculata (L.) Walp.]. J Soil Sci Plan Nutr.12(1): 1-14.

Siqueira J, Soares C, Santos J, Schneider J, Carneiro M (2007) Micorrizas e degradação do solo: caracterização, efeitos e ação recuperadora. In: Ceretta CA, Silva LS, Reichert JM (eds) Tópicos em ciência do solo. Sociedade Brasileira de Ciência do Solo, Viçosa. pp. 219-306.

Skovran E, Martinez-Gomez NC (2015) Just add lanthanides. Science. 348(6237): 862-863.

Usepa (2007) Method 3051A microwave assisted acid digestion of sediments, sludges, soils and oils. In: United States Environmental Protection Agency (ed) SW-846: Test methods for evaluating solid waste, physical/chemical methods. Environmental Protection Agency, Washington, 1-30.

Wang Z, Liu D, Lu P, Wang C (2001) Accumulation of rare earth elements in corn after agricultural application. J Environ Qual. 30(1): 37-45.

Xie Z, Zhu J, Chu H, Zhang Y, Zeng Q, Ma H, Cao Z (2002) Effect of lanthanum on rice production, nutrient uptake, and distribution. J Plant Nutr. 25(10): 2315-2331.

Zhou $M$, Gong X, Wang Y, Liu C, Hong $M$, Wang L, Hong $F$ (2011) Improvement of cerium on photosynthesis functions of maize under magnesium deficiency. Biol Trace Elem Res. 142(3): 760-772. 